\title{
Device Physics of Nanoscale Interdigitated Solar Cells
}

Conference Paper NREL/CP-520-43303

May 2008

\section{Preprint}

W.K. Metzger and D. Levi

National Renewable Energy Laboratory

Presented at the 33rd IEEE Photovoltaic Specialists Conference San Diego, California

May 11-16, 2008
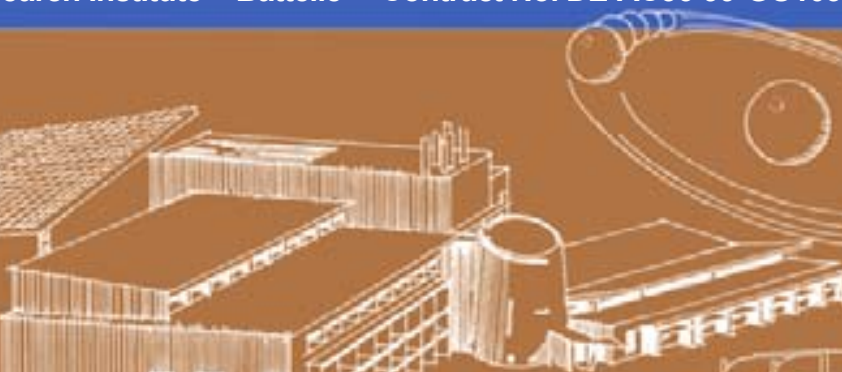


\section{NOTICE}

The submitted manuscript has been offered by an employee of the Midwest Research Institute (MRI), a contractor of the US Government under Contract No. DE-AC36-99G010337. Accordingly, the US Government and MRI retain a nonexclusive royalty-free license to publish or reproduce the published form of this contribution, or allow others to do so, for US Government purposes.

This report was prepared as an account of work sponsored by an agency of the United States government. Neither the United States government nor any agency thereof, nor any of their employees, makes any warranty, express or implied, or assumes any legal liability or responsibility for the accuracy, completeness, or usefulness of any information, apparatus, product, or process disclosed, or represents that its use would not infringe privately owned rights. Reference herein to any specific commercial product, process, or service by trade name, trademark, manufacturer, or otherwise does not necessarily constitute or imply its endorsement, recommendation, or favoring by the United States government or any agency thereof. The views and opinions of authors expressed herein do not necessarily state or reflect those of the United States government or any agency thereof.

Available electronically at http://www.osti.gov/bridge

Available for a processing fee to U.S. Department of Energy and its contractors, in paper, from:

U.S. Department of Energy

Office of Scientific and Technical Information

P.O. Box 62

Oak Ridge, TN 37831-0062

phone: 865.576 .8401

fax: 865.576 .5728

email: mailto:reports@adonis.osti.gov

Available for sale to the public, in paper, from:

U.S. Department of Commerce

National Technical Information Service

5285 Port Royal Road

Springfield, VA 22161

phone: 800.553 .6847

fax: 703.605.6900

email: orders@ntis.fedworld.gov

online ordering: http://www.ntis.gov/ordering.htm 


\title{
DEVICE PHYSICS OF NANOSCALE INTERDIGITATED SOLAR CELLS
}

\author{
Wyatt K. Metzger and Dean H. Levi \\ National Renewable Energy Laboratory, Golden, CO 80401
}

\begin{abstract}
Recently there has been theoretical and experimental evidence for the formation of nanodomains in polycrystalline $\mathrm{Cu}(\mathrm{In}, \mathrm{Ga}) \mathrm{Se}_{2}$ that may form complex threedimensional intertwined $p-n$ networks. This has caused some researchers to consider such a network as the operative method of current collection in $\mathrm{Cu}(\mathrm{In}, \mathrm{Ga}) \mathrm{Se}_{2}$ solar cells. Quantitative modeling is required to test this assumption and evaluate the relevant physics. This paper uses multidimensional device simulation to explore the physics and solar cell performance of interdigitated $p-n$ junctions for material parameters relevant to the postulated conditions. The physics at the nanoscale are often not intuitive, but the results indicate that interdigitated junctions can improve solar cell performance relative to corresponding planar-junction devices and achieve reasonably high solar cell efficiencies with semiconductor materials that have less than optimal electro-optical properties.
\end{abstract}

\section{INTRODUCTION}

Photovoltaic solar cells based on polycrystalline $\mathrm{Cu}(\mathrm{In}, \mathrm{Ga}) \mathrm{Se}_{2}$ (CIGS) hold great promise as a carbon-free energy source. High-efficiency cells are grown in nonstoichiometric concentration ratios, which suggests that spontaneous separation between alpha and beta phases may play a part in achieving high efficiency. Stanbery has argued that the $\alpha$ and $\beta$ phases may segregate on the nanometer scale to form an interpenetrating threedimensional network of charge-separating junctions that act as the operative method of current collection in CIGS solar cells[1]. There has been some experimental support of this concept. Transmission electron microscopy studies on CIGS films by Yan et al revealed strong chemical fluctuations at the nanometer scale and the formation of Cu-poor and Cu-rich nanodomains.[2] They concluded that the Cu-poor and Cu-rich regions may form $n$-type and $p$-type regions respectively so that a CIGS film is indeed composed of a complex nanoscale $p-n$ junction network. In this study we utilize two-dimensional modeling to evaluate these theories through numerical analysis of interdigitated $p-n$ junction thin film solar cells. The width of the $p$ and $n$ regions is varied from $10 \mathrm{~nm}$ to $1 \mu \mathrm{m}$ to evaluate how scale affects transport and device performance.

\section{DEVICE MODEL}

The schematic in Fig. 1 indicates the model structure. The CIGS, ZnO, and CdS layers are $3 \mu \mathrm{m}, 200 \mathrm{~nm}, 50 \mathrm{~nm}$ thick respectively. The AM1.5 solar spectrum is incident

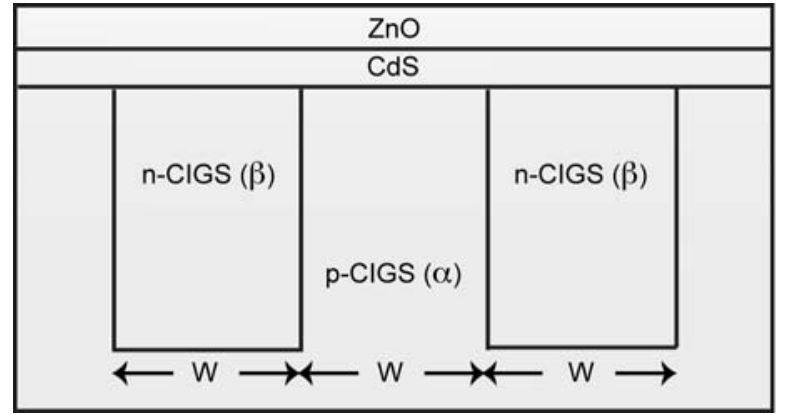

Figure 1. Schematic representation of the interdigitated CIGS solar cell model.

on the $\mathrm{ZnO}$ surface, and $\sim 90 \%$ of the light is absorbed within $1 \mu \mathrm{m}$ of CdS/CIGS interface. The CIGS absorber layer has alternating $p$ and $n$ regions with equal width $W$. The $n$ regions extend to a depth of $2.5 \mu \mathrm{m}$ below the $\mathrm{CdS} / \mathrm{CIGS}$ junction. The $n$ regions are modeled as $\beta-$ phase CIGS, and the $p$ regions are modeled as $\alpha$-phase CIGS. The material parameters are chosen so that the CIGS $\alpha$-like. phase has a bandgap of $1.15 \mathrm{eV}$, which is typical of high-efficiency devices.[3] The $\beta$-like phase is assigned a bandgap of $1.43 \mathrm{eV}$. The conduction- and valence-band offsets between the two phases are $\sim 20$ and $260 \mathrm{meV}$, respectively, based on values reported in the literature.[4] The optical constants for the $\alpha$ and $\beta$ phases, $\mathrm{CdS}$, and $\mathrm{ZnO}$ are adapted from Refs. [5,6,7] respectively. Experimental observations indicate that nanodomains formed by chemical fluctuations do not have abrupt interfaces or strong interfacial defect densities and therefore may be relatively free of interface recombination.[8] Consistent with these observations interfacial recombination is set to zero in the calculations for this study. We examine two cases, high quality and low quality CIGS material. For mobility and lifetime parameters, "high-quality" CIGS is modeled using a deep defect with a minority-carrier lifetime of $5 \mathrm{~ns}$, and hole and electron mobilities of 12.5 and $100 \mathrm{~cm}^{2} / \mathrm{Vs}$, respectively. On the other hand, "low-quality" CIGS is modeled with a minority-carrier lifetime of $500 \mathrm{ps}$, and hole and electron mobilities of 1.25 and $10 \mathrm{~cm}^{2} / \mathrm{ss}$, respectively.

Several studies have indicated that CIGS has strong potential fluctuations and that the material is strongly compensated.[9] It is possible that these fluctuations are caused by variations in $p$ and $n$ doping across nanodomains. Experimental estimates of the total electron and hole densities are $\sim 10^{18} / \mathrm{cm}^{3}$, with a net free-carrier concentration of $\sim 10^{16}$ holes $/ \mathrm{cm}^{3}$. $[10,11]$ Accordingly, the electron concentration in the $n$ regions is set at $6 \times 10^{17}$ $\mathrm{cm}^{3}$, and the hole concentration in the $p$ regions is set to 
either $6 \times 10^{17}$ or $6.2 \times 10^{17} \mathrm{~cm}^{3}$. Other material parameters for $\alpha-$ and $\beta$-phase CIGS, CdS, and $\mathrm{ZnO}$ are listed in Table I. If CIGS absorber layers form a spontaneous 3-D $p-n$ network, it is likely that some $p$ and $n$ regions will be surrounded by regions of the opposite type and not be directly connected to their respective contacts. Consequently, it is acknowledged that Fig. 1 is a simple and optimistic model of this concept.

The computational modeling simultaneously solves the Poisson and electron and hole continuity equations, which incorporate drift and diffusion current terms and energy density boundary equations at the heterointerfaces. These interfaces are considered abrupt and defined by the material bandgaps and electron affinities using the Anderson model.[12] The drift-diffusion equations are derived from the Boltzmann transport equation based on certain physical assumptions.[12] Some of these assumptions break down for small values of $W$ when the bandgap and impurity concentrations fluctuate on a scale smaller than the carrier mean free path length and quantum confinement influences band structure. However, calculating the quantum physics of nanoscale fluctuations, simulating individual particle transport, and incorporating this into a rigorous solar device model is extraordinarily complex and in practice not necessarily any more accurate. As a semiclassical approach, here the driftdiffusion equations are extended to the nanoscale.

Table I. This table lists the material parameters used in the simulations. The rows correspond to bandgap $\left(E_{g}\right)$, electron affinity $(\chi)$, electron and hole mobility $\left(\mu_{\mathrm{e}}, \mu_{\mathrm{h}}\right)$, electron or hole concentration $(n, p)$, dielectric constant $\left(\varepsilon / \varepsilon_{0}\right)$, electron and hole effective masses $\left(m_{e} / m_{\circ}, m_{h} / m_{\circ}\right)$, midgap-state concentration and the corresponding electron and hole cross-sections $\left(\sigma_{e}, \sigma_{h}\right)$, front and back contact recombination velocities $\left(S_{e}, S_{h}\right)$, and reflectivity. The entries with a slash (/) specify the values for high/low- quality material.

\begin{tabular}{|c|c|c|}
\hline Bulk Parameters & $\alpha$-CIGS & $\beta$-CIGS \\
\hline $\mathrm{E}_{\mathrm{g}}(\mathrm{eV})$ & 1.15 & 1.43 \\
\hline$\chi(\mathrm{eV})$ & 4.6 & 4.62 \\
\hline$\mu_{\mathrm{e}}\left(\mathrm{cm}^{2} / \mathrm{V}-\mathrm{s}\right)$ & $100 / 10$ & $100 / 10$ \\
\hline$\mu_{\mathrm{h}}\left(\mathrm{cm}^{2} / \mathrm{V}-\mathrm{s}\right)$ & $12.5 / 1.25$ & $12.5 / 1.25$ \\
\hline$n, p\left(\mathrm{~cm}^{-3}\right)$ & $6.0 \times 10^{17}$ & varied \\
\hline$\varepsilon / \varepsilon_{0}$ & 13.6 & 13.6 \\
\hline $\mathrm{m}_{\mathrm{e}} / \mathrm{m}_{\circ}$ & 0.09 & 0.09 \\
\hline $\mathrm{m}_{\mathrm{h}} / \mathrm{m}_{\circ}$ & 0.72 & 0.72 \\
\hline Midgap state $\left(\mathrm{cm}{ }^{-3}\right)$ & $\mathrm{N}_{\mathrm{o}}: 1 \times 10^{15}$ & $\mathrm{~N}_{\mathrm{o}}: 1 \times 10^{15}$ \\
\hline$\sigma_{\mathrm{e}}\left(\mathrm{cm}^{2}\right)$ & $2 \times 10^{-14 /-13}$ & $2 \times 10^{-14 /-13}$ \\
\hline$\sigma_{\mathrm{h}}\left(\mathrm{cm}^{2}\right)$ & $2 \times 10^{-14 /-13}$ & $2 \times 10^{-14 /-13}$ \\
\hline Surface Parameters & Front & Back \\
\hline $\mathrm{S}_{\mathrm{e}}\left(\mathrm{cm}_{\mathrm{s}}\right)$ & $10^{7}$ & $10^{7}$ \\
\hline $\mathrm{S}_{\mathrm{h}}(\mathrm{cm} / \mathrm{s})$ & $10^{7}$ & $10^{7}$ \\
\hline Reflectivity & 0.05 & 0 \\
\hline
\end{tabular}

\section{RESULTS AND DISCUSSION}

Figure 2 illustrates the relative energy and band bending for the valence and conduction bands at a depth of $1.5 \mu \mathrm{m}$ into the absorber for (a) $W=250 \mathrm{~nm}$, (b) $W=50 \mathrm{~nm}$, and (c) $\mathrm{W}=10 \mathrm{~nm}$. For the value of $\mathrm{W}=250 \mathrm{~nm}$, sufficient charge is available within each nanodomain for diffusion between $p$ - and $n$-regions to produce significant band bending. As $W$ decreases, the band bending is still significant but the band offsets become more important. For very small $W$, there is insufficient charge to induce band bending and the bandgap and offsets dominate lateral band alignment. The overall position of the bands relative to the Fermi level depends on the net doping, that is $p-n$. For very small $\mathrm{W}$, the size of the conduction band oscillations are
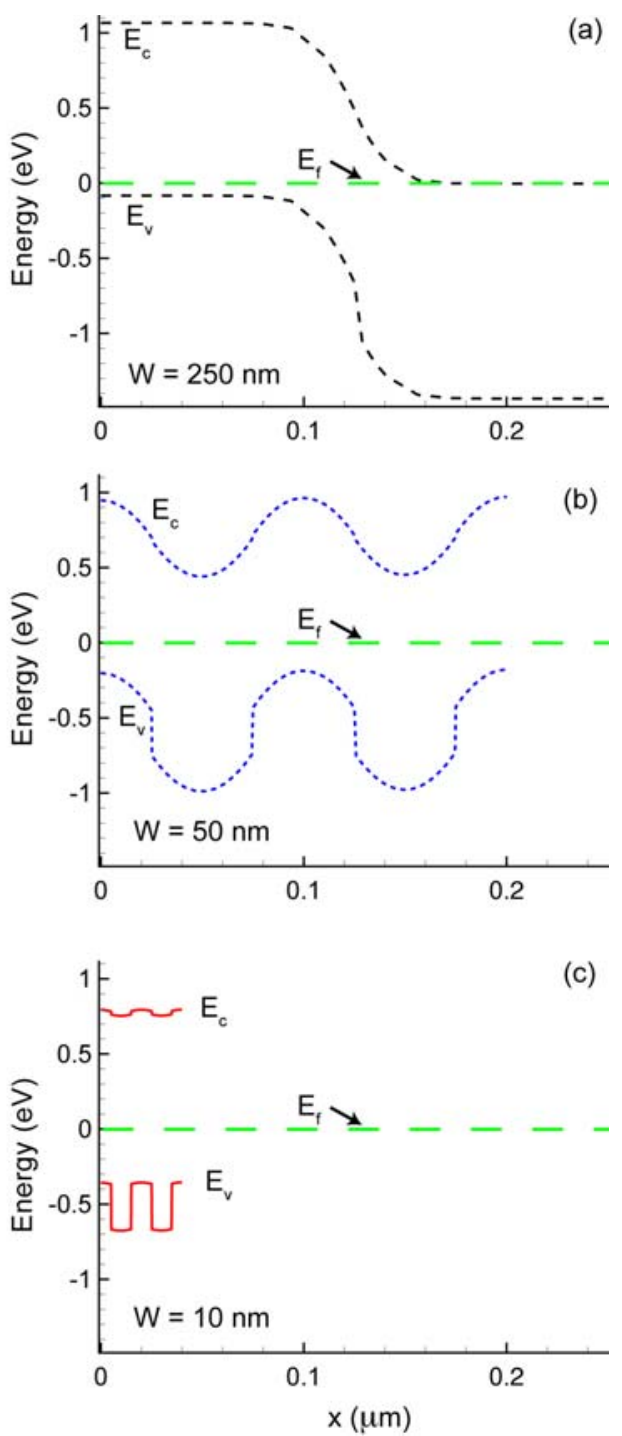

Figure 2. Conduction and valence bands with no applied bias or illumination for a horizontal cut $1.5 \mu \mathrm{m}$ into the CIGS layer when W equals (a) $250 \mathrm{~nm}$ (b) $50 \mathrm{~nm}$ and (c) $10 \mathrm{~nm}$. The Fermi level is at $0 \mathrm{eV}$ (dashed green line). The conduction- and valence-band offsets between the two phases are $\sim 20$ and $260 \mathrm{meV}$, respectively. 
determined by the $\alpha$ - to $\beta$-type conduction band offset of $20 \mathrm{meV}$, so electrons are able to diffuse across both alpha and beta regions. Conversely, holes are confined within the $\alpha$-phase or p-type regions by the $\sim 260 \mathrm{meV}$ band offset in the valence band.

An intuitive way to visualize the interdigitated nanodomain cell is as a series of vertically aligned $p-n$ junction solar cells stacked next to each other. For large values of $\mathrm{W}$ the band bending between $n$ - and $p$-type regions contributes to large lateral electric fields that induce lateral charge separation. For very small values of $\mathrm{W}$, the lateral fields diminish in strength and the device acts more like a standard 1-D solar cell. For intermediate values of $W$ the properties transition between these two extremes. Figure 3 illustrates the dependence of $\mathrm{J}_{\mathrm{sc}}, \mathrm{V}_{\mathrm{oc}}$, and efficiency on nanodomain width W. Fill factor is not plotted because it follows the same general trends as $V_{\text {oc.[13] }} \quad$ Each graph presents 4 cases; two different relative $n$ - and $p$-doping levels, and high and low quality CIGS for each level of doping. The electron concentration in the $n$ regions is set at $6 \times 10^{17} \mathrm{~cm}^{-3}$, and the hole concentration in the $p$ regions is set to either $6 \times 10^{17}$ or $6.2 \times 10^{17}$. In figure 3 these two cases are expressed in terms of the net carrier density $p-n$.

The photocurrent depends primarily on how many minority carriers are generated within a diffusion length of the depletion region of a collecting junction. Here, as is typical of thin-film solar cells, most carriers are generated within $1 \mu \mathrm{m}$ of the incident surface. In a planar device, a junction runs parallel to the incident surface, and collects carriers efficiently down to a certain depth. In an interdigitated junction this is no longer the case. Carriers generated very close to the incident surface, but in the horizontal center of an n-type or p-type region, may not be collected. For example, in the low-quality case the diffusion length is $\sim 100 \mathrm{~nm}$. When $\mathrm{W}=1 \mu \mathrm{m}$, many minority carriers generated in the central portion of the $p$ and $\mathrm{n}$ regions will be more than $100 \mathrm{~nm}$ from a $p-n$ junction. Consequently, the short-circuit current density $\mathrm{J}_{\mathrm{sc}}$ is inferior to a comparable planar device. In the highquality case the diffusion length is $\sim 1 \mu \mathrm{m}$. The same geometrical considerations are still present, but the impact on $\mathrm{J}_{\mathrm{sc}}$ is less. As $\mathrm{W}$ decreases from $1 \mu \mathrm{m}$ to $50 \mathrm{~nm}$, the average distance minority carriers must travel to reach a junction decreases and minority-carrier collection steadily improves. In fact, inspection of Fig. $2 b$ indicates that for $W$ $=50 \mathrm{~nm}$, carriers are almost always generated in a charge separating field. Hence, $J_{s c}$ is nearly equal for the lowquality and high-quality materials. Interestingly, as $W$ is reduced below $50 \mathrm{~nm}$, the photocurrent decreases. The source of this behavior will be described later.

The open-circuit voltage $\left(\mathrm{V}_{\mathrm{oc}}\right)$ depends on multiple factors including recombination, dark current, band bending, and short-circuit current. As W decreases from 1 $\mu \mathrm{m}$ to $50 \mathrm{~nm}, \mathrm{~V}_{\text {oc }}$ trends in the opposite direction of $\mathrm{J}_{\mathrm{sc}}$. For large values of $\mathrm{W}$, there is sufficient charge transfer to create very large built-in potentials between $p$ and $n$ regions. This can be seen in Figure 2, where for $W=250$
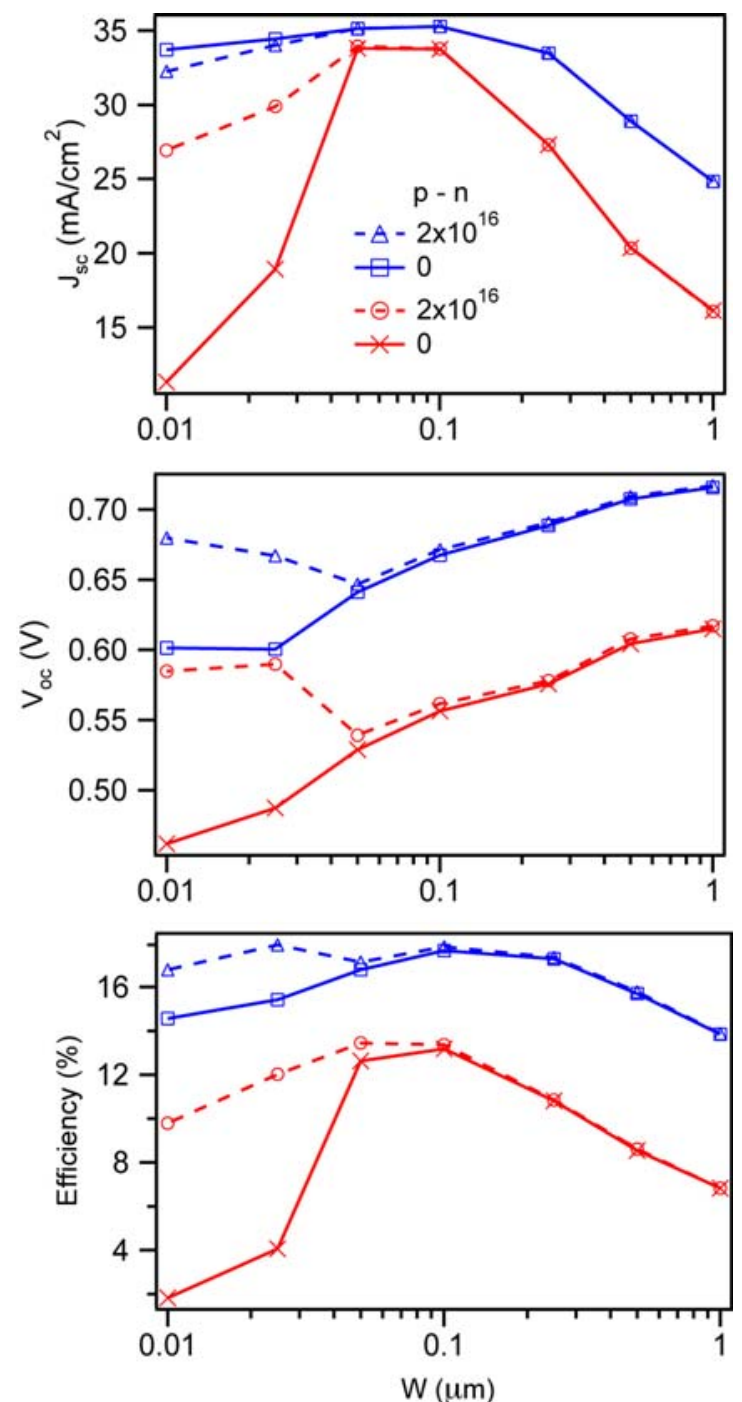

Figure 3. Calculated values of $\mathrm{J}_{\mathrm{sc}}, \mathrm{V}_{\mathrm{oc}}$, and efficiency as a function of doping density and nanodomain width $W$. Solid lines are for doing levels of $6 \times 10^{17} \mathrm{~cm}^{-3}$ in both the $\mathrm{n}$ - and p-type regions, while dashed lines are for $6 \times 10^{17} \mathrm{~cm}^{-3}$ in the $\mathrm{n}$ - regions and $6.2 \times 10^{17} \mathrm{~cm}^{-3}$ in the p-regions. Blue lines and symbols are for high quality CIGS and red lines and symbols are for low quality CIGS.

$\mathrm{nm}$, the built-in potential exceeds $1 \mathrm{~V}$. As $\mathrm{W}$ decreases to $50 \mathrm{~nm}$, the band bending decreases to the order of 500 $\mathrm{mV}$. At the same time, the width of the depletion regions increases because there is less charge transfer. Dark current is proportional to the number of carriers that are thermally generated either in a depletion region or within a diffusion length of a collecting junction. Hence, reducing $W$ increases the dark current which contributes to a reduction in $\mathrm{V}_{\text {oc. }}$.

The trends change as $\mathrm{W}$ decreases below $50 \mathrm{~nm}$ because the interdigitated region begins to behave as a quasi one-dimensional layer rather than a multidimensional $p-n$ network. As is illustrated in Fig.2c, when $W$ is decreased below $50 \mathrm{~nm}$, the band bending between the $p$ and $n$ regions is nearly eliminated. For $\mathrm{W}=$ 
$10 \mathrm{~nm}$, the conduction band offset between $n$ - and $p$ regions is just $20 \mathrm{meV}$, and electrons are unconfined. If the $p$ and $n$ regions are evenly doped at $6 \times 10^{17} \mathrm{~cm}^{-3}$, the base Fermi level is commensurate with an intrinsic layer. On the other hand, if the interdigitated $p$ and $n$ regions have $6.2 \times 10^{17}$ and $6.0 \times 10^{17}$ carriers $/ \mathrm{cm}^{3}$, respectively, the Fermi level is nearly equivalent to a uniform $p$-CIGS layer with $1 \times 10^{16}$ holes $/ \mathrm{cm}^{3}$, which is half the difference of the $p$ and $n$ doping levels.

Once $\mathrm{W}$ decreases below $50 \mathrm{~nm}$, the lateral fields are relatively weak compared to the field at the CIGS/CdS metallurgical junction. So the CIGS/CdS junction dominates the $\mathrm{J}-\mathrm{V}$ characteristics. In a one-dimensional device, a more heavily doped base layer decreases the depletion width, lowers Jsc, and increases the $\mathrm{V}_{\text {oc. }}$. Fig. 3 shows that the same trends occur for the interdigitated device when $W$ is less than $50 \mathrm{~nm}$, however, the Fermi level or effective doping is determined by the average of the constituent $p$ and $n$ regions. As the difference in the interdigitated $p$ and $n$ regions becomes more $p$ type, the $\mathrm{CIGS/CdS}$ depletion width decreases, $V_{\text {oc }}$ increases, and $\mathrm{J}_{\mathrm{sc}}$ decreases.

Overall, the results indicate that interdigitated $p$ and $n$ regions increase efficiency relative to a comparable planar junction device for low-quality material when $W$ equals 50 or $100 \mathrm{~nm}$. Otherwise, the interdigitated device gives very respectable efficiency and $\mathrm{J}-\mathrm{V}$ characteristics that are consistent with actual CIGS solar cells, but the performance is not significantly increased relative to a planar junction. Performance can be enhanced if the offsets between the $p$ and $n$ regions form a robust type-II network to effectively separate electrons and holes even when $\mathrm{W}$ is significantly less than $50 \mathrm{~nm}$.[14] But here the conduction band offsets between the alpha- and betaphase regions are too small to achieve this.

\section{CONCLUSIONS}

For the simple model of nanoscale interdigitated solar cells used in this study we find when $\mathrm{W}$ is too thick, the geometry is not ideal for effective current collection. As W decreases, most carriers are collected without significant reduction in $\mathrm{V}_{\text {oc }}$, producing higher efficiency. When $\mathrm{W}$ falls below a critical value, the material begins to act more like a 1D structure in the sense that the dominant collection field is set by the $\mathrm{ZnO} / \mathrm{CdS} / \mathrm{CIGS}$ junction rather than the lateral fields in the CIGS. Hence, for W less than $50 \mathrm{~nm}$, performance separates based on the value of $p-n$ in the CIGS layer. $V_{o c}$ is optimum when there is maximal band bending and minimal dark current, which occurs at large W. As $W$ decreases, so does the band bending, field strength, and $V_{\text {oc. }}$. As $\mathrm{W}$ decreases below $50 \mathrm{~nm}$, the fact that the dominant collection field is set by the $\mathrm{ZnO} / \mathrm{CdS} / \mathrm{CIGS}$ junction rather than the lateral fields becomes apparent.

The alpha- beta-phase matrix can potentially produce robust device performance in line with the J-V characteristics observed by experimentalists in the labs. However, it generally does not give substantial improvement over a simple 1D structure, or a more compelling argument for how $19 \%$ cells are made than traditional 1D models.

\section{ACKNOWLEDGEMENTS}

This work was supported by the US DOE under Contract No. DE-AC36-99G010337.

\section{REFERENCES}

1 B.J. Stanbery, Proceedings of the $31^{\text {st }}$ IEEE Photovoltaics Specialist Conference (IEEE, New York, 2005), p. 355.

2 Y. Yan, R. Noufi, K.M. Jones, K. Ramanathan, M.M. AlJassim, and B.J. Stanbery, Appl. Phys. Lett 87, 121904 (2005). Y. Yan, R. Noufi, and M. M. Al-Jassim, Phys. Rev. Lett. 96, 205501 (2006).

3 K. Ramanathan et al, Prog. Photovoltaics 11, 225 (2003).

4 S.B. Zhang, S.H. Wei, A. Zunger, and H. KatayamaYoshida, Phys. Rev. B 57, 9642 (1998). T. Irie, S. Endo, and S. Kimura, Solar Cells 16, 1 (1986).

5 S.H. Han, C. Persson, F.S. Hasoon, H.A. Al-Thani, A.M. Hermann, and D.H. Levi, Phys. Rev. B 74, 085212 (2006), optical values for $\mathrm{Culn}_{3} \mathrm{Se}_{5}$ were adjusted to a bandgap of $1.43 \mathrm{eV}$ or $1.45 \mathrm{eV}$ for Models II and III, respectively. Near bandgap values adjusted based on unpublished transmission data from Dr. David Albin of NREL.

6 S. Ninomiya and S. Adachi, J. Appl. Phys. 78, 1183 (1995). Also, unpublished data on polycrystalline CdS by David Albin at NREL.

7 S. Adachi, Optical Constants of Crystalline and Amorphous Semiconductors (Kluwer Academic Publishers, Massachusetts, 1999).

8 Y. Yan, R. Noufi, K.M. Jones, K. Ramanathan, M.M. AlJassim, B.J. Stanberry, Appl. Phys. Lett. 87, 121904 (2005).

9 B. J. Stanbery, Critical Reviews in Solid State and Materials Sciences, 27, 73 (2002).

10 I. Dirnstorfer, D. M. Hofmann, M. D. Lampert, F. Karg, and B. K. Meyer, Phys. Stat. Sol. (a) 168, 163 (1998).

11 J. T. Heath, J. D. Cohen, W. N. Shafarman, D. X. Liao, and A. A. Rockett, Appl. Phys. Lett. 80, 4540 (2002).

12 S. Selberherr, Analysis and Simulation of Semiconductor Devices (Springer-Verlag, NY, 1984).

13 M.A. Green, Solar Cells (Prentice-Hall, Englewood Cliffs, 1982).

14 W.K. Metzger, Journal of Applied Physics 103, 094515 (2008). 


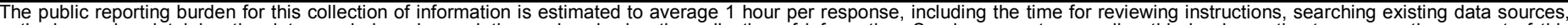

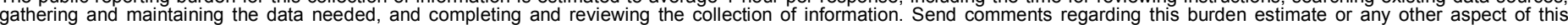

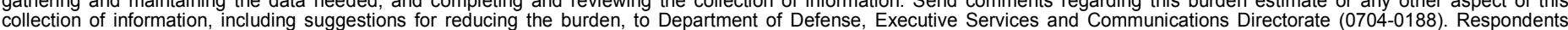

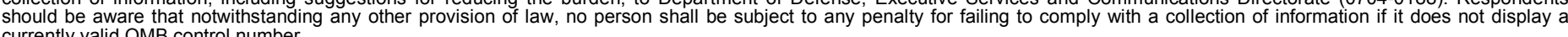

PLEASE DO NOT RETURN YOUR FORM TO THE ABOVE ORGANIZATION.

\section{REPORT DATE (DD-MM-YYYY) \\ May 2008 \\ 2. REPORT TYPE \\ Conference Paper}

4. TITLE AND SUBTITLE

Device Physics of Nanoscale Interdigitated Solar Cells: Preprint
3. DATES COVERED (From - To) 11-16 May 2008

5a. CONTRACT NUMBER

DE-AC36-99-G010337

5b. GRANT NUMBER

5c. PROGRAM ELEMENT NUMBER

5d. PROJECT NUMBER

NREL/CP-520-43303

5e. TASK NUMBER

PVA73101

5f. WORK UNIT NUMBER
7. PERFORMING ORGANIZATION NAME(S) AND ADDRESS(ES)

National Renewable Energy Laboratory

1617 Cole Blvd.

Golden, CO 80401-3393
8. PERFORMING ORGANIZATION REPORT NUMBER

NREL/CP-520-43303

9. SPONSORING/MONITORING AGENCY NAME(S) AND ADDRESS(ES)

10. SPONSOR/MONITOR'S ACRONYM(S) NREL

11. SPONSORING/MONITORING AGENCY REPORT NUMBER

12. DISTRIBUTION AVAILABILITY STATEMENT

National Technical Information Service

U.S. Department of Commerce

5285 Port Royal Road

Springfield, VA 22161

\section{SUPPLEMENTARY NOTES}

14. ABSTRACT (Maximum 200 Words)

Recently there has been theoretical and experimental evidence for the formation of nanodomains in polycrystalline $\mathrm{Cu}(\mathrm{In}, \mathrm{Ga}) \mathrm{Se} 2$ that may form complex three-dimensional intertwined p-n networks. This has caused some researchers to consider such a network as the operative method of current collection in Cu(In,Ga)Se2 solar cells. Quantitative modeling is required to test this assumption and evaluate the relevant physics. This paper uses multidimensional device simulation to explore the physics and solar cell performance of interdigitated $p-n$ junctions for material parameters relevant to the postulated conditions. The physics at the nanoscale are often not intuitive, but the results indicate that interdigitated junctions can improve solar cell performance relative to corresponding planarjunction devices and achieve reasonably high solar cell efficiencies with semiconductor materials that have less than optimal electro-optical properties.

\section{SUBJECT TERMS}

CIGS; PV; nanoscale solar cells; polycrystalline; quantitative modeling; interdigitated junctions;

\begin{tabular}{|c|c|c|c|c|}
\hline \multicolumn{3}{|c|}{ 16. SECURITY CLASSIFICATION OF: } & \multirow{2}{*}{$\begin{array}{l}\text { 17. LIMITATION } \\
\text { OF ABSTRACT } \\
\text { UL }\end{array}$} & \multirow{2}{*}{$\begin{array}{ll}\text { 18. } & \text { NUMBER } \\
\text { OF PAGES }\end{array}$} \\
\hline $\begin{array}{l}\text { a. REPORT } \\
\text { Unclassified }\end{array}$ & $\begin{array}{l}\text { b. ABSTRACT } \\
\text { Unclassified }\end{array}$ & $\begin{array}{l}\text { c. THIS PAGE } \\
\text { Unclassified }\end{array}$ & & \\
\hline
\end{tabular}

19a. NAME OF RESPONSIBLE PERSON

19b. TELEPHONE NUMBER (Include area code) 